\title{
Coleta seletiva: perspectivas de sustentabilidade nas associações de catadores de resíduos sólidos na cidade de Fortaleza (CE)
}

\footnotetext{
Este estudo objetiva analisar as perspectivas de sustentabilidade das Associações de Catadores de Resíduos Sólidos nas dimensões social, econômica, ambiental e institucional diante da implantação do programa de coleta seletiva, tendo como locus o Município de Fortaleza, no Estado do Ceará. Nesta investigação foi utilizado o método qualitativo, sendo sua análise de natureza explicativa e descritiva, fundamentada em pesquisa bibliográfica- documental e de campo, realizada em 09 associações de catadores de resíduos secos e úmidos que participam do Fórum Lixo e Cidadania e recebem apoio das políticas ambientais da Secretaria de Urbanização e Meio Ambiente. Nas dimensões apontadas foram constados: maior organização contábil, melhor nível de conscientização sobre a importância da coleta, aparecimento de novos negócios, aprimoramento da política interna de organização, aumento de parcerias entre catadores e indústrias etc. A implantação de uma nova cooperativa, promete ser um canal para a formação do espírito associativista e cooperativista entre as associações e os grupos de catadores.
}

Palavras-chave: Estudos Socioambientais; Coleta Seletiva; Resíduos Sólidos; Organizações; Não Governamentais (ONGs).

\section{Selective collection: perspectives of sustainability in associations of solid waste pickers in the city of Fortaleza (CE)}

\begin{abstract}
This study aims to analyze the prospects for sustainability of Associations of Solid Waste Pickers in social, economic, environmental and institutional respect to the implementation of the selective collection program, with the locus Municipality of Fortaleza, in Ceará. In this qualitative research method was used, with its analysis of explanatory and descriptive nature, based on documentary and bibliographical and field research conducted in 09 associations of collectors of wet and dry waste participating in the Waste and Citizenship Forum and receive support from the political the environmental SEUMA. The dimensions given were constados: high accounting organization, better level of awareness about the importance of data collection, development of new businesses, improving the internal politics of the organization, increasing partnerships between collectors and industries etc.. The implementation of a new cooperative, promises to be a channel for the formation of the associative and cooperative spirit between the associations and groups of collectors. naphthalene.
\end{abstract}

Keywords: Social and Environmental Studies; Selective collection; Solid Waste; Organizations; Nongovernmental Organizations (NGOs).

Topic: Engenharia Sanitária

Reviewed anonymously in the process of blind peer.

Antônio Jackson Alcantara Frota

Universidade de Fortaleza, Brasil

http://lattes.cnpq.br/1759153138195547

bianapsq@hotmail.com

Mônica Mota Tassigny

Ecole des Hautes Études en Sciences Sociales, França

http://lattes.cnpq.br/4109325305631925

bianapsq@hotmail.com

Fabiana Pinto de Almeida Bizarria

Universidade de Fortaleza, Brasil

http://lattes.cnpq.br/0008637422329772

bianapsq@hotmail.com

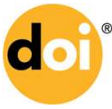

DOI: $10.6008 / S P C 2179-6858.2016 .003 .0011$
Received: 10/03/2016

Approved: 09/08/2016

\author{
Marcus Vinícius de Oliveira Brasil \\ Universidade de Fortaleza, Brasil \\ http://lattes.cnpq.br/1806063717574977 \\ bianapsq@hotmail.com \\ Isadora Margarete Guimarães da Silva \\ Universidade de Fortaleza, Brasil \\ http://lattes.cnpq.br/0118042215230818 \\ bianapsq@hotmail.com
}

Referencing this:

FROTA, A. J. A.; TASSIGNY, M. M.; BIZARRIA, F. P. A.; BRASIL, M. V. O. SILVA, I. M. G.. Coleta seletiva: perspectivas de sustentabilidade nas associações de catadores de resíduos sólidos na cidade de Fortaleza (CE). Revista Ibero-Americana de Ciências Ambientais, v.7, n.3, p.125143, 2016. DOI: http://doi.org/10.6008/SPC2179-6858.2016.003.0011 


\section{INTRODUÇÃO}

Um dos maiores problemas das cidades de grande densidade urbana e suas regiões metropolitanas é a falta de tratamento adequado do lixo ou resíduo reciclável nas áreas de aterros sanitários, uma vez que resíduos tóxicos contaminam o solo e as fontes de água subterrânea, além de produzir gases por incineradores ou combustão que poluem o ar de forma não controlada (GOUVEIA, 1999).

A crise ambiental que o lixo provoca tem a ver com a própria construção social de um modo capitalista que vem sendo estruturado por fases históricas, a saber: até a década de 1970, os impactos ambientais eram percebidos frente ao crescente número da população; já a partir da década de 1970, estes impactos eram notados pelo crescente processo de produção (BRINGHENTI, 2004).

Entretanto, a partir da década de 1990, os problemas ambientais advêm de um descontrole do consumismo, por isso mesmo, falar de desenvolvimento sustentável sem comprometer o meio que se vive e o restante do planeta exige uma boa gestão de resíduos sólidos, capazes de minimizar os impactos negativos que atingem a natureza e maximizar o ciclo de vida útil dos diversos materiais capazes de se renovarem e oferecerem valor às necessidades da comercialização.

As consequências dos problemas ambientais não atingem a população de forma proporcional, mas recaem sobre as classes sociais menos privilegiadas que, geralmente, se estabelecem próximas ou mesmo nos locais degradados, devido ao lançamento de resíduos." (RIBEIRO; LIMA, 2000). Uma sociedade sustentável supre que todos os cidadãos tenham o mínimo necessário para uma vida digna e que ninguém absorva bens, recursos naturais e energéticos que sejam prejudiciais a outros. Isso significa erradicar a pobreza e definir o padrão de desigualdade aceitável (NASCIMENTO, 2012).

Assim, torna-se desafiadora a implantação de um plano de coleta seletiva que contemple projetos que almejem o melhoramento da qualidade de vida dos cidadãos, das associações de catadores de resíduos sólidos e que corresponda aos crescentes elementos sociais, ambientais, econômicos e institucionais de cidades com intensa urbanização, como, por exemplo, na cidade de Fortaleza, metrópole que vem num acelerado processo de desenvolvimento (IBGE, 2010). Observa-se, portanto, uma preocupação de cunho administrativo tanto para o poder público como para o setor privado.

Fortaleza, a Capital cearense, tem 2.452.185 habitantes (IBGE, 2010) e se destaca pelo aumento populacional e o crescente polo de industrialização. Entretanto, apesar dessa realidade em fase de expansão, a cidade ainda convive com quadros de miséria. "Estima-se que 800 comunidades de baixa renda inseridas em áreas de risco, bem como o antigo lixão do Jangurussú completam o conjunto de fatores de exclusão social da cidade, cuja população não participa da sociedade de consumo". (GRADVOHL, 2010). Apesar da ocorrência de ascensão de classes sociais, durante a década de 2000 , as desigualdades e a visibilidade da miséria ainda são percebidas.

A sustentabilidade dos grandes centros urbanos passa, também, pelo estímulo à reciclagem, pelo incentivo da coleta seletiva consciente e participativa, questão na qual a cidade de Fortaleza começa a se organizar de forma proativa com a participação de associações de catadores. 
A intenção é que a estrutura de um programa de coleta seletiva beneficie a sociedade através de uma gestão mais integrada, dando um foco ambiental, social, econômico e institucional. Insistir na separação entre o interesse econômico e o social ou o ambiental e o institucional pode repercutir de forma negativa, pois em cada área existem a necessidade e o desafio de interação com outras dimensões. O processo de recuperação do ambiente passa por uma maior ação antrópica, onde o homem é o agente que levanta propostas de desmaterialização da economia e gera um padrão civilizatório em longo prazo (NASCIMENTO, 2012).

Diante do contexto da relevância da coleta seletiva para a sustentabilidade de grandes centros urbanos, a presente pesquisa se propõe a investigar quais elementos alicerçam as perspectivas de sustentabilidade nas associações de catadores de resíduos sólidos urbanos em Fortaleza que norteiam as dimensões: social, econômica, ambiental e institucional.

\section{REVISÃO TEÓRICA}

\section{Sustentabilidade nas Associações de Reciclagem}

A sustentabilidade é a consequência natural de um padrão de organização complexa, apresentando cinco características básicas: a 'Interdependência', que se designa ao entendimento de que o comportamento de um único indivíduo influenciará nas outras vidas envolvidas no ecossistema; a 'Reciclagem', como um passo relevante para realimentar os ecossistemas, uma vez que a natureza é cíclica em seus movimentos naturais; a 'Parceria', sendo elemento fundante da sustentabilidade, o que significa a cooperação mútua entre os agentes dos ecossistemas; a 'Flexibilidade', diante dos possíveis desequilíbrios das condições ambientais mutáveis, faz-se necessária a volta ao equilíbrio das normas, uma vez que o meio ambiente está em continua transformação; e a 'Diversidade', já que o meio ambiente, por se constituir uma rede de sistemas decorrentes da biodiversidade, exige, das realidades humanas, a mesma elasticidade adaptativa que o meio ambiente (CAPRA, 1996).

A noção de sustentabilidade e sua aplicabilidade têm se diluído em um "mantra" equivocado ou, até mesmo, são utilizadas para se criar um discurso de desenvolvimento econômico (CAVALCANTI, 2012). Falase em sociedades sustentáveis, pois o processo social é rapidamente modificável e, por isso mesmo, ninguém pode garantir a permanência sustentável deste ou daquele país ao passar dos anos e em desenvolvimento ambientalmente sustentável, pois quanto mais crescimento social, menos se tem meio ambiente na perspectiva micro ecológico (CAVALCANTI, 2012). “Crescimento implica sempre menos meio ambiente. [...] quanto mais gente na terra, quanto mais produção econômica, quanto mais artefatos construídos, tanto menos natureza." (CAVALCANTI, 2012).

Sustentabilidade releva-se como um processo socioeconômico capaz de levar à minimização do uso da matéria e energia, é a capacidade de diminuir os impactos ambientais; é maximizar o bem-estar coletivo, primando por uma sociedade que não seja ameaçada pelos riscos à vida humana; além de se alcançar, com eficiência, o uso dos recursos naturais (CAVALCANTI, 2012). 
A noção de sustentabilidade tem duas raízes, sendo uma biológica, com a capacidade de reprodução e recuperação dos diversos ecossistemas, e a outra fincada na ciência econômica, com a motivação do crescimento social (NASCIMENTO, 2012). Vislumbra-se um caminho de compreensão da formação do conceito de sustentabilidade que parte da dimensão ambiental para a realidade social e do contexto social para a dimensão econômica (NASCIMENTO, 2012).

As dimensões do desenvolvimento sustentável - ambiental, social e econômico - são caminhos entrelaçados que exigem ações claras de conservação e dosagem justa dos agentes humanos. Acrescenta-se a estas dimensões uma a mais, que é a institucional, uma vez que as organizações, sejam elas públicas ou privadas, têm influência direta na sustentabilidade das diversas realidades existentes, de forma a influenciar o ambiente, a convivência e o progresso social, bem como o desenvolvimento econômico, de forma a não comprometer negativamente as outras dimensões.

A primeira dimensão do desenvolvimento sustentável normalmente citada é a ambiental. Ela sugere que o modelo de produção e de consumo seja compatível com a base material em que se assenta a economia, com o subsistema do meio natural. Trata-se, portanto, de produzir e consumir de forma a garantir que os ecossistemas possam manter sua autorreparação ou capacidade de resiliência. A segunda dimensão, a econômica, supre o aumento da eficiência da produção e do consumo como economia crescente de recursos naturais, como delicados e mal distribuídos, como a água e os minerais. Trata-se daquilo que alguns denominam como ecoeficiência, que supre uma contínua inovação tecnológica (NASCIMENTO, 2012).

Entretanto, adotar um estudo sobre sustentabilidade a partir dessas dimensões apresenta-se como um desafio, uma vez que a literatura sobre o assunto diferencia suas conceituações e, dependendo da ótica que se quer investigar a realidade, a questão do poder é esquecida; a questão institucional se torna elemento de marketing verde; a questão política em torno da reflexão do desenvolvimento sustentável se torna interesse pessoal, gerando crises entre governo, organização e sociedade civil.

\section{Legislação e Implantação do Programa de Coleta Seletiva}

O Município de Fortaleza possui uma legislação para a gestão dos resíduos sólidos fundamentada na lei de no 8.408, de 24 de dezembro de 1999, que legisla sobre a responsabilidade e o manejo dos resíduos em grande quantidade, em conformidade com o decreto de № 10.696, de 02 de fevereiro de 2000, que estabelece a execução dos serviços na área de resíduos sólidos urbanos; o decreto de no 11.260 , de 30 de setembro de 2002, que regulamenta a disposição de containers em vias ou logradouros públicos; o decreto de $n$ ㅇ 11.633, de 18 de maio de 2004, que estabelece a missão da Secretaria de Urbanização e Meio Ambiente (SEUMA), de analisar o Plano Gestor de Resíduos Sólidos do Município; e o decreto de no 11.646, de 31 de maio de 2004, que alterou o decreto de no 10.696, de 02 de fevereiro de 2000, sobre a execução do serviço de gerenciamento dos resíduos sólidos urbanos. O artigo 10 da lei municipal de no 8.408/09 determina:

O produtor de resíduos sólidos cujo peso específico seja maior que $500 \mathrm{~km} / \mathrm{m} 3$, ou cuja quantidade produzida exceda o volume, de 100 litros ou $50 \mathrm{~kg} / \mathrm{dia}$, o que seja proveniente de estabelecimentos domiciliares, públicos, comerciais, industriais e de serviços, será denominado grande gerador e responsável pelos serviços de acondicionamento, coleta, armazenamento, transporte, tratamento e destinação final, devendo custeá-los. 
Nesse sentido, os grandes geradores são responsáveis por 7\% do total de resíduos destinados ao Aterro Sanitário Metropolitano Oeste de Caucaia (ASMOC) no ano de 2011, quando, aproximadamente, $135.457,02 \mathrm{t}$ foi originada pelos grandes geradores (SANETAL, 2012).

Diante desse contexto a coleta seletiva tem se tornado um instrumento concreto redução de desperdiço, de mudança de comportamento ambiental e de reutilização dos bens de consumo nas cidades (RIBEIRO; LIMA, 2000).

Segundo Gradvohl (2010), a linha do tempo sobre a busca de uma institucionalização da coleta seletiva em Fortaleza ocorreu desde o período de 1956 a 1960, no extinto 'Lixão do João Lopes', localizado no bairro do Monte Castelo. Em seguida, o 'Lixão da Barra do Ceará', no período de 1961 a 1965, que acolheu os rejeitos de grande parte da população fortalezense. Chegando a sua capacidade total, exigiu a abertura de outro espaço, o 'Lixão Buraco da Jia', no bairro do Antonio Bezerra, que sobreviveu apenas de 1966 a 1967, dado o crescente número de habitantes da região oeste de Fortaleza, que exigiu a sua eliminação.

De 1968 a 1977, a Prefeitura de Fortaleza construiu o 1ํ Coletor Compactador, no bairro do Henrique Jorge, com a finalidade de diminuir a grande quantidade de resíduos sólidos que aumentavam, com a nova configuração urbana da cidade. Foi a partir dessas diversas tentativas que surgiu o 'Lixão do Jangurussu' que funcionou, na natureza de lixão a céu aberto, de 1978 a 1989, para, somente em 1998, a Prefeitura de Fortaleza, em acordo firmado em parceria com a Prefeitura Municipal de Caucaia, criar o Aterro Sanitário Metropolitano Oeste de Caucaia (ASMOC). Nessa permuta, as duas gestões municipais firmaram uma parceria com a doação do terreno por parte do Governo do Estado: Fortaleza forneceria a logística dos dois municípios, e Caucaia assumiria os passivos ambientais.

Gradvohl (2010) sistematizou o processo de criação e desenvolvimento do programa de coleta em diversos períodos, compreendidos de 1994 a 1995; 1995 a 1996; 1996 a 1997; 1997 a 1998; 1998 a 1999; 2000 a 2004; 2004 a 2007.

No período de 1994 a 1995, o aterro do Jangurussu esteve em plena atividade, chegando a receber 27 toneladas de papel, plástico, vidros e metais. Os catadores eram, cada vez mais, inseridos numa realidade marginal, e os atravessadores, chamados de sucateiros, era quem faturavam com a exploração de mão de obra de baixo custo e da venda do material coletado em unidades de reciclagem.

Especulou-se, nesse momento histórico, a criação de um incinerador e a criação de três aterros sanitários a serem criados nos municípios de Caucaia, Maracanaú e Aquiraz. Essas estratégias foram amplamente rejeitadas pelos trabalhadores do Aterro do Jangurussu, que tiveram apoio de outros interessados, como OAB, Igreja Católica e grupos organizados da sociedade em prol da sustentabilidade do meio ambiente.

Em 1995, o governo criou um programa de educação ambiental para coleta e tratamento de resíduos recicláveis no bairro do Pirambu, uma espécie de cooperativa que recolhia resíduos e os transformava em material sustentável, diminuindo a quantidade enviada ao aterro do Jangurussu.

No período de 1995 a 1996, aconteceu a criação oficial da primeira entidade de classe dos catadores do Lixão do Jangurussu, que iniciou a inserção dos catadores de lixo em uma nova realidade, incentivando, 
ainda, a alfabetização entre esses profissionais, que logo se tornou uma realidade.

Gradvohl (2010) afirma que, de 1996 a 1997, o Projeto Sociedade Recicladora Pirambu (SOCRELP) começou a se distanciar de seu objetivo original, além da crise que se estabeleceu, pela demanda insuficiente pela reciclagem. Por isso, no dia 28 de abril de 1996, esse programa, que nasceu para educar ambientalmente a população, foi reconhecido apenas como limitado à auto-sustentação, o que levou a SOCRELP a adotar uma nova estratégia, denominada 'Consórcio do Lixo', ampliando a ideia de educação ambiental para uma política socioambiental, passando a sobreviver com o apoio de diversas parcerias locais.

Entre 1997 e 1998, com a crescente institucionalização do setor industrial de reciclagem no Estado do Ceará, foi criado o Sindicato das Empresas de Reciclagem de Resíduos Sólidos Domésticos e Industriais do Estado do Ceará (SINDIVERDE), como apoio da Federação das Indústrias do Ceará (FIEC) e do Serviço de Apoio às Micro e Pequenas Empresas do Estado do Ceará (SEBRAE-CE), uma espécie de sindicato patronal. "O modelo tinha tudo para dar certo. Era constituído inicialmente de 25 empresas, e mesclava 2 tipos de categorias: os setores da indústria de papelão, plástico, metal e vidro, além de empresas e comunidades organizadas que tratavam resíduos e comercializavam para as indústrias." (GRADVOHL, 2010). Nesse período, a Prefeitura de Fortaleza discutiu a formação de um consórcio entre municípios, para o aproveitamento de resíduos, que enfrentou obstáculos referentes à educação na origem e à logística.

O período entre 1998 e 1999 ficou marcado pela comprovação de que a Usina do Jangurussu era insustentável, pois não tinha demanda suficiente de material adquirido por indústrias de reciclagem. Assim, o aterro que virou lixão e sobreviveu dessa forma por 20 anos, enfrentando um contexto paradoxo de fome e injustiças, além do consumismo e do acúmulo. De 1998 aos dias atuais, o aterro do Jangurussu se tornou um local de transbordo para o ASMOC, com algumas presenças de operários para catação das esteiras que ainda produzem grande quantidade de chorume.

De 2000 a 2004, Fortaleza começou a viver um contínuo processo de conscientização socioambiental, amparado por estratégias que surgiram do setor privado, porém o fator delimitador do avanço da institucionalização de um programa de coleta seletiva se deu diante da falta de continuidade da gestão municipal. Constata-se, com a mudança partidária de alguns gestores, que os projetos são descontinuados, implicando um retrocesso à questão socioambiental do município. "A descontinuidade, fato que transtornou uma sociedade, é causada não por conflitos ideológicos, mas por ciúmes entre diferentes facções ideológicas e entre diferentes facções públicas, mesmo que essas pertençam a um único partido político" (GRADVOHL, 2010).

De 2004 a 2007, a ideia de modelos sustentáveis de coleta seletiva começou a tomar maior proporcionalidade, uma vez que a noção ética, socioambiental, econômica e institucional se tornou exigência de civilidade e índice de desenvolvimento humano. Diante do aumento do consumismo em todo o planeta, tornaram-se necessários projetos tecnicamente planejados, com adequação à cultura da população. Diante dessa constatação, a criação do 'bônus social' estimulou a população, de forma econômica, a se reeducar ambientalmente que “(...) passou a ser a ferramenta mestra de integração dos aspectos econômicos e 
ambiental, levando, assim, o lixo reciclável, antes exposto ao meio ambiente, até o setor produtivo reciclador". (GRADVOHL, 2010).

A partir de 2007, o Governo Federal instituiu, para toda a nação, a chamada Universalização do Saneamento Básico, pela lei de №. 11.445, consolidando as agendas nacional, estadual e municipal, no que se refere à limpeza urbana e ao manejo de resíduos sólidos. Em seguida, por meio da Lei de no 12.305/ 2010 o Presidente da República formalizou a Política Nacional de Resíduos Sólidos, obrigando o poder público e o setor privado a definirem responsabilidades compartilhadas.

Diante dessa nova realidade, a gestão municipal de Fortaleza iniciou em 2012 a construção do Plano Municipal de Gestão Integrada de Resíduos Sólidos, encomendando 04 relatórios sobre o assunto realizados nos meses de março e abril de 2012. Esses relatórios são a base para o programa de coleta seletiva adotado no município de Fortaleza e foram construídos pela Engenharia e Consultoria em Saneamento e Meio Ambiente de Florianópolis (SANETAL- SC), com contrato firmado em 07 de dezembro de 2011.

A cidade de Fortaleza, atualmente, é apontada com 98,75\% de coleta de resíduos domiciliares (IBGE, 2010), o que se refere apenas à coleta porta a porta pela empresa de coleta urbana.

\section{METODOLOGIA}

Este trabalho foi desenvolvido com base em diálogos com os autores consultados na revisão bibliográfica, que tratam da coleta seletiva de resíduos, em busca de comprovar, ou não, a hipótese teórica da viabilidade sustentável do programa de coleta seletiva nos âmbitos econômico, social, ambiental e institucional, nas Associações de Catadores de Resíduos Sólidos de Fortaleza.

A presente pesquisa adotou o método qualitativo, trabalhando no universo dos significados, com dados intrínsecos às relações, não delimitado as mensurações (MINAYO, 2004). “O processo de condução de investigação qualitativa reflete uma espécie de diálogo entre os investigadores e os respectivos sujeitos, dado estes não serem abordados por aqueles de uma forma neutra." (BOGDAN; BIKLEN, 1994).

A investigação assume natureza explicativa, considerando que visa esclarecer quais fatores contribuem, de alguma forma, para a ocorrência de determinado fenômeno, na perspectiva de pesquisa de campo, tendo em vista uma investigação empírica, realizada no local onde ocorre ou ocorreu um fenômeno, ou que dispõe de elementos para explicá-lo (VERGARA, 2000).

A pesquisa de campo foi realizada em nove associações de catadores de resíduos secos e úmidos no Município de Fortaleza, que participam do Fórum Lixo e Cidadania e recebem o apoio da Diretoria de Políticas Ambientais da SEUMA. São elas: Associação Viva a Vida; Associação Brisamar; Associação dos Recicladores Amigos da Natureza (ARAN); Associação Reciclando; Associação dos Agentes Ambientais Rosa Virginia; Associação Ecológica dos Coletores de Material Reciclável da Serrinha e Adjacências (ACORES); Associação Maravilha; Associação dos Catadores do Pirambu (SOCRELP); Associação dos Catadores do Jangurussu (ASCAJAN).

A escolha por estas associações deu-se pela importância de sua formalização junto aos órgãos públicos e às organizações parceiras na reciclagem de resíduos sólidos urbanos, em parceria com a Secretaria 
de Urbanização e Meio Ambiente do Município (SEUMA), por terem mais de 04 anos de fundação e apresentarem produtividade significativa para visualização de retorno aos seus associados, bem como aos seus parceiros, sejam pelo fornecimento de resíduos ou pela aquisição comercial dos mesmos.

Durante os meses de junho a julho de 2013, foram realizadas 02 entrevistas gravadas, tendo por interlocutores o secretário executivo da SEUMA e o secretário para a implantação do programa de Coleta Seletiva em Fortaleza. Foi utilizado nas entrevistas um roteiro semiestruturado, aplicado pelo próprio pesquisador. Nos meses de agosto a setembro, foram realizadas 09 entrevistas com 20 perguntas gravadas com os diretores das associações pesquisadas.

A análise dos resultados da pesquisa realizou-se por uma abordagem qualitativa que como uma maneira de pensar sobre os dados e o mundo no qual se vive, questionando-se o que se vê e se ouve, elevando ao nível abstrato (STRAUSS; CORBIN, 2008). Diante dessa identidade metodológica, o perfil do investigador se revelará da seguinte forma:

(1) Capacidade de retroceder e analisar criticamente as situações;

(2) Capacidade de reconhecer a tendência em direção às bias;

(3) Capacidade de pensar abstratamente;

(4) Capacidade de ser flexível e aberto a críticas construtivas;

(5) Sensibilidade com as palavras e as ações dos informantes;

(6) Um sentido de absorção e devoção ao processo de trabalho. (STRAUSS; CORBIN, 2008).

A realidade das 09 associações foi observada à luz do programa em construção de Coleta Seletiva no Município, de forma a conhecer os desafios e as perspectivas sustentáveis nas dimensões econômica, social, ambiental e institucional, que foram geradas em seus associados, uma vez que eles estão ligados as associações que possuem a autorização e o acompanhamento da SEUMA.

\section{RESULTADOS}

\section{Perspectivas de Sustentabilidade das Associações: Dimensão Social}

Na dimensão social se vislumbra, ainda que parcial contínuo apoio de projetos originados tanto pela gestão pública, seja na esfera federal, estadual ou municipal, quanto originado da iniciativa privada, através das instituições religiosas como a Cáritas Arquidiocesana de Fortaleza, indústrias de reciclagem, empresas de vários setores produtivos, além de uma crescente conscientização dos residentes na Capital. O apoio as associações, gerando, selecionando e fornecendo resíduos, separando úmido do seco, aos profissionais de catação que passam de porta em porta ou de ponto em ponto já é expressão dessa conscientização (RIBEIRO; LIMA, 2000). A diretora 5 da associação E levanta a seguinte questão:

O que é Adote um Catador? É você ter consciência de separar seu material, colocar num cantinho, material limpo, sem mau cheiro, sem resto de comida, e aí destinar àquele catador, não colocar na calçada, receber aquele catador com dignidade, como um trabalhador, então já tem muitas famílias que fazem isso, e aí ele vai, passa lá no dia certo, de 15 em 15 dias, vem toda semana, aí ele vai pegar esse material já certo (45 anos e 10 anos de associação).

Na perspectiva do trabalhador, percebe-se a crescente valorização e o respeito pela necessidade de se apoiar e investir nas associações de catadores. Constata-se que no Brasil os programas de coleta estão 
partindo da capacidade da população de reduzir, reutilizar e reciclar, pois, para a sociedade, representa uma possibilidade de alternativa e oportunidade de limpeza urbana e geração de renda, como pode se perceber pelo relato da entrevistada acima (BRINGUENTI, 2004).

Os apoios das instituições religiosas e de órgãos públicos tendem a se ampliar, uma vez que parte da capacitação oferecida às associações pesquisadas advém destas instituições, que acompanham por meio de pesquisas e relatórios, pelo Fórum Lixo e Cidadania, com a Rede de Catadores, como afirma o responsável pelas políticas ambientais da SEUMA:

O real ganho é porque hoje você tem esse pessoal incluso no projeto e hoje tem uma vida diferenciada da que ele tinha há 4 ou 5 anos atrás, que eles não tinham uma unidade construída em relação ao trabalho. A capacitação de recursos, hoje, eles têm um acompanhamento da Cáritas e do SEBRAE, onde estão sendo feitas capacitações, então, isso hoje melhorou muito ao que era 5 a 6 anos atrás (48 anos; secretário desde 2009).

Para uma maior sustentabilidade das associações de catadores, é importante a fiscalização do Conselho Tutelar da Infância e Adolescência para coibir o trabalho infantil. Aquelas que conseguem envolver os filhos dos associados nos programas de educação e baixa renda recebem mais incentivos e têm livre acesso à participação de editais como, por exemplo, da Fundação Nacional de Saúde (FUNASA) que proporcionarem investimentos para as associações. No entanto, associações que são displicentes no acompanhamento desta causa são exortadas pela Rede de Catadores e podem ser excluídos do Fórum Lixo e Cidadania, como afirma o responsável pelas políticas ambientais da SEUMA:

A gente vem tentando minimizar ao máximo a questão desse processo, hoje é praticamente do pessoal que trabalha de forma associada, porque não existe mais trabalho infantil, se existir é de grupos que estão isolados dentro do município, que é o que estamos procurando hoje, agregar estes catadores que estão soltos no município de Fortaleza, para que eles venham para dentro do sistema participar de associações a partir da rede de catadores, ou seja, trabalhar de forma cooperativa (48 anos; secretário desde 2009).

A educação, tão importante para o exercício da boa cidadania, também é uma exigência e uma perspectiva social para as associações, uma vez que surgem iniciativas de alfabetização noturna na rede municipal de ensino. Entretanto, esta perspectiva só logrará êxito com maior apropriação por parte das diretorias das associações que, além de estimular os seus associados a participarem, devem acompanhar a assiduidade dos seus membros, como afirma a diretora 9 da associação I:

Porque a gente apoia quem não sabe ler e escrever, inclusive a própria presidente não sabia ler, nem escrever e eu também não sabia ler e nem escrever, estou aprendendo agora, graças a Deus tudo o que eu queria era aprender a escrever o meu nome (36 anos; 12 anos de associação).

Outro aspecto social que cria uma perspectiva mais sustentável às associações é a conscientização da saúde pública e a proteção da insalubridade a que estão expostos seus associados-catadores. A FUNASA tem capacitado e exige em seus editais de investimento, que as associações invistam nesta conscientização e no acompanhamento dos riscos que os catadores correm em contato com resíduos contaminados. Este dado está em conformidade com a afirmação de Gradvohl (2010) sobre as diversas enfermidades a que os catadores estão diariamente expostos, como relata a diretora 9 da associação I:

Melhorou sim, porque no antigo lixão nós tínhamos muitos riscos, nós adoecíamos, levava furada de agulha e hoje graças a Deus aqui dentro da associação I não acontece isso, porque primeiro nós não trabalhamos com material hospitalar, nós trabalhamos com coleta de 
material limpo, material orgânico é fora, graças a Deus que nós não corremos esse risco hoje (36 anos; 12 anos de associação).

A dignidade de exercer uma atividade remunerada é um elemento que evidencia uma maior perspectiva social de sustentabilidade nas associações, ou seja, ser catador de resíduos sólidos presentes numa associação confere status em relação aos que não pertencem.

A ideia de ter uma identidade associativa, de agregação coletiva expressa para o catador e para a associação uma simbiose de interesses e conquistas, gerando para a sociedade uma ideia de organização, de seriedade e de profissionalismo em relação à atividade de catação.

A associação necessita de catadores para sua sobrevivência, o catador necessita da associação para conquistar reconhecimento social, e a sociedade em geral expressa a atenção e a necessidade crescente da associação como se pode perceber diante do relato do diretor 2 da associação B:

Melhorou eu não sei se todos, mas do meu lado, o lado da Dona Doquinha, da Leninha, que tinham um problema, e depois que ela começou a trabalhar, diz ela que melhorou muito, por ela quase ser paralítica, aí o médico disse que se fizesse exercícios, aí caminhasse, aí ela começou a trabalhar na reciclagem, e hoje ela é uma mulher saudável, alegre, diz que jamais ela deixaria o trabalho de lá, e eu também, pra mim melhorou muito, porque além de ganhar meu dinheiro, eu tenho aquela ocupação, eu tenho muito conhecimento com as pessoas e pra mim melhorou bastante. Em termo financeiro a gente ganha pouco, e não posso dizer que eu nunca mais comprei roupas, tenho duas carroças que não é essas coisas, hoje em dia você vê que eu tenho dificuldades com uma entrevista dessas, mas de primeiro eu tinha era medo das pessoas, hoje em dia eu estou mais desenvolvido, a gente também viaja para fora, São Paulo, Rio, todo canto a gente vai pela associação. Então é assim, é melhor estar na associação do que não estar na associação (62 anos e 03 anos de associação).

A gestão do Município de Fortaleza está envolvida com a execução de 04 galpões de triagem a fim de acolher os resíduos sólidos para a reciclagem nos seguintes bairros: João XXIII, Jangurussu, Bom Sucesso e Planalto Universo. Também se almeja a criação de um galpão para cada regional da Capital. Esta iniciativa expressa uma melhor estrutura para as instalações para o recebimento dos resíduos selecionados pela coleta das associações.

Outro aspecto é a melhoria no fornecimento básico da assistência social de cada associação que se engaja no fornecimento destes galpões, proporcionado às associações participantes da coleta seletiva assistência por meio de equipe multidisciplinar para a melhoria e qualidade de vida dos seus associados.

Porque eles vão ser mais respeitados, eles vão ter um assistente social apoiando, eles vão ter um psicólogo apoiando, eu acho até que o modelo do galpão do Bom Sucesso é um modelão, porque ali vão ver que tem local salubre, tem uma sala de reunião, ali podem ter um atendimento de psicólogo, e um médico, e uma assistente social para eles, e eles teriam nesse caso aqui volume e renda, porque o volume e a renda do catador tá muito associado, aliás para qualquer coisa, o volume do lixo não tem valor agregado, então só o volume gera renda, quer dizer seria um depósito respeitado (Responsável pela coleta seletiva do município, 54 anos).

\section{Perspectivas de Sustentabilidade das Associações: Dimensão Econômica}

A presente pesquisa investigou que as diretorias das associações, em conjunto com os conselhos fiscais, estão mais atentas e organizam de forma mais contábil sua sustentabilidade financeira, uma vez que o volume da coleta em Fortaleza tem aumentado significativamente. Por ser uma cidade turística, surge a 
necessidade de um controle interno e externo mais profissionalizado e menos amador, estabelecendo metas, bem como porcentagem de participação dos sócios e dos custos fixos e investimentos na própria associação, como relata a diretora 5 da associação $\mathrm{E}$ :

A associação, desde quando ela foi fundada, a gente definiu que o percentual de $70 \%$ da venda é destinado para o catador e $30 \%$ é mantido na associação, para que a associação arque com seus custos, água, luz, telefone, gasolina. Então esse custo de manter a associação fica com esses $30 \%$ e $70 \%$ é para o catador. Então a gente calcula o preço, se eu vendo $1 \mathrm{~kg}$ de papelão a 0,10 centavos; 0,07 centavos é do catador e 0,03 centavos fica para a associação, para exatamente não está passando por grandes necessidades de está faltando dinheiro para pagar luz, ou então cada um está dando uma coisinha (45 anos, 10 anos de associação).

A participação livre de editais públicos para que as associações possam apresentar seus projetos para obter recursos é um elemento que impulsiona a sustentabilidade econômica das associações. Foi possível observar nas sedes das associações equipamentos como prensa, esteira, lousa, caminhões, carrinhos de coleta conquistados por meio de participação de editais. Uma vez que a lei 12.305, de 2010 propõe maior apoio da gestão pública à gestão de resíduos sólidos, vislumbra-se, nos próximos anos, o aumento de editais para aprimoramento e profissionalização das associações, como se pode notar pelo relato da diretora 5 da associação E:

O nosso equipamento está sendo adquirido pela própria associação, nós temos equipamentos grandes, nós participamos do projeto da FUNASA e aí a gente adquiriu um caminhão e um triciclo para fazer a coleta que vem dos órgãos federais. Na época do Presidente Lula, ele fez um decreto que diz que todos os órgãos federais devem fazer sua seleção de materiais e destinar a uma associação de catadores, então sempre que os órgãos federais fazem sorteio e chamam a gente, ai é eeito essa coleta. Temos alguns equipamentos que já foram doados com os projetos deles, temos esses equipamentos doados pela Ambev, que nos doou uma prensa e uma balança, porque eles vieram a associação e estavam de acordo com os projetos. Então a gente tem esses equipamentos doados pela Ambev e o caminhão e o triciclo que já foi projeto da FUNASA (45 anos; 10 anos de associação).

Diante dos incentivos econômicos as associações não legalizadas tendem a criar seu Cadastro Nacional de Pessoa Jurídica (CNPJ), em vista da participação de compra e venda de material, da participação mais ampla para ser reconhecido pela SEUMA e pelas instituições apoiadoras. Como relata a diretora 3 da associação C:

Como a minha associação é registrada, eu posso fechar um contrato com os órgãos federais para eu receber o material, mas aí tinha alguns grupos que eles não podiam, porque não tinham os documentos do CNPJ, o que eles pediam. (46 anos; 10 anos de associação).

Uma nova perspectiva econômica para as associações é o apoio com investimento em equipamentos e recursos financeiros do Banco Nacional de Desenvolvimento (BNDES) para a aquisição de máquinas de filtragem do óleo de frituras que, refinado, está, no presente momento, com perspectivas de crescente aumento de compra por parte da Petrobras. Além do óleo, a borra de cor âmbar retirada do óleo é adquirido para a confecção de telhas, ou seja, uma nova oportunidade de negócio. As associações que investem em galpões, máquinas e associados capacitados para esta atividade terão um retorno financeiro expressivo nos próximos anos com Óleo e Gorduras Residuais (OGR), conforme se pode observar nas figuras 26 e 27 como relata abaixo a diretora 6 da associação $\mathrm{F}$ : 
Aqui hoje funciona a estação do óleo, a rede já tem um projeto que ela trabalha com óleo de fritura, esses óleos que as pessoas fritam batatinhas, os restaurantes que fazem muitas frituras. Então hoje nós já trabalhamos com esse material aqui, temos cinco trabalhadores ali trabalhando, ganhando seu dinheirinho, 500 reais líquido mais as passagens e mais o almoço, e queremos que isso cresça, que não é para ficar só nos cinco, queremos que isso nos abranja cada vez mais, essa é uma parceria com a Petrobras, a gente vende para Petrobras para fazer biodiesel para os carros (51 anos; 12 anos de associação).

Em 2014, a gestão municipal com a articulação da SEUMA dará início ao projeto dos ecopontos, locais onde os cidadãos poderão levar seu resíduo reciclável, tendo como projeto piloto 02 ecopontos no bairro Varjota, por ser uma área de grande concentração de bares, restaurantes e hotéis. A Secretaria de Políticas Ambientais do município ampliará o ecoponto para o material seletivo das empresas, uma vez que o material coletado será de grande quantidade, sendo destinada a coleta do ecoponto para as associações. Esta logística será garantida pela gestão municipal.

Então essas quatro associações que vão ser administradas pela rede é que vão receber o material desse ponto de coleta. Claro que inicialmente nós vamos utilizar de um teste piloto, nós vamos também ter o ecoponto. O ecoponto é o quê? É um terreno numa área, no caso da Varjota, nós vamos ter dois ecopontos, e esse ecoponto vai receber o material que vem dos restaurantes, bares e hotéis, ou seja, o ponto da coleta. Ele vai ser para resíduos domiciliares, você, na sua casa, separa o material leva ao ponto de coleta e recebe o bônus, e o ponto de coleta fornece para a rede de catadores. O ecoponto é diferente, você tem uma empresa, você tem o maior volume, então o seu material seletivo vai para o ecoponto, e o ecoponto manda para a rede de catadores. A diferença é que aqui vai o CNPJ e aqui vai a pessoa física (responsável pela coleta seletiva do município, 54 anos).

As associações serão estimuladas a agregarem em sua receita financeira a atividade da coleta de alguns tipos de elementos orgânicos para a compostagem. Têm certos os compradores, seja a própria prefeitura para suas escolas, postos de saúde e repartições sejam os empresários do ramo da adubação e jardinagem. Este dado corrobora a afirmação de Bley Jr. (2001) de que o resíduo orgânico, ao invés de ser um elemento de impacto poluidor, passa a ser numa gestão qualificada, uma forte oportunidade de negócio e empreendimento social. O que se estimula como um elemento a mais de agregação de valor captado mensalmente pela associação virá da criação de núcleos de produção nos bairros, que são definidos pelo responsável pela coleta seletiva do município:

Então você tem que começar também a criar núcleos de produção nos bairros. O que é isso? Lá no Jangurussu tem uma unidade de tratamento de coco verde parada, tem, na praia do futuro, em torno de 700 mil cocos verdes, pessoas que tomam água de coco e jogam no meio ambiente esses 700 mil cocos verdes por mês. Isso, quem é responsável pela coleta desse material no final são os próprios restaurantes, não é a prefeitura, então a nossa proposta é que esses cocos verdes e mais a poda da cidade criem uma unidade, que a prefeitura faça a jardinagem das praças delas utilizando composto orgânico, porque não podemos fazer um núcleo de produção e compostos orgânicos nos bairros (responsável pela coleta seletiva do município, 54 anos).

O trabalho de coleta de resíduos orgânicos demanda capacitação dos catadores, maquinário, e uma logística mais elaborada que facilite para o catador encaminhar o material coletado a uma associação, ao recolhê-lo nestes núcleos de produção nos bairros. A caracterização dos resíduos sólidos é especialmente relevante, considerando a necessidade de se definir bem a forma mais adequada da disposição final, bem como o melhor sistema de tratamento possível (ROVIRIEGO, 2005). 
No Ceará, constata-se o aumento da instalação de indústrias de reciclagem, com altos índices de recuperação de materiais, aumentando perceptivamente a exigência da qualidade do material coletado (IBAM, 2001). Para as associações, se torna possível negociar com uma carta maior de clientes industriais, como se identifica diante da pergunta feita pelo pesquisador ao responsável pela coleta seletiva do município: “No município de Fortaleza existem parceiros privados suficientes para comprar esta coleta?":

$100 \%$. Basta lhe dizer o seguinte, hoje nós estreamos em Fortaleza de uma forma geral que vai para Caucaia, botando construção civil e tudo dentro, você tem algo em torno de 4.400 toneladas por dia. Vamos imaginar que são $20 \%$ desses centros de resíduos recicláveis, a gente estima aí algo de 15 mil toneladas, de 15 a 20 mil toneladas por mês de resíduos recicláveis, resíduos esses que interessam para a indústria no Ceará. Então hoje nós não temos isso dentro das indústrias. O que é que acontece, tem indústria como a Gerdau, que compra sucata na África para aumentar a empresa dela aqui no Ceará, se tivesse todo ácido ela compraria aqui (Responsável pela coleta seletiva do município, 54 anos).

\section{Perspectivas de Sustentabilidade das Associações: Dimensão Ambiental}

A perspectiva que baseia maior sustentabilidade das associações de catadores é a crescente conscientização ao denominar o que pode ser realmente descartado como rejeito e a grande parte do material que pode ser reutilizado.

A consciência ambiental do cidadão, do associado-catador e da própria associação 'E influenciada diante da publicidade fundamentada pelo marketing ambiental, estimulada pelas indicações da Agenda 21, como se pode perceber pelo seguinte relato do responsável pelas políticas ambientais do município:

Nós vínhamos fazendo uma articulação no sentido de tentar melhorar isso, e já foram construídos, em relação a esses eventos em Fortaleza, que nós estamos trabalhando neste sentido, campanhas de educação ambiental no município de Fortaleza. Agora, na Copa das Confederações, nós fizemos um trabalho em parceria com as associações de catadores e Arena Castelão, na qual está sendo proposto um convênio entre elas para que possam trabalhar em todos os eventos que acontecerem na Arena Castelão. Trabalhamos também no Fortal, isso tentando ajudar economicamente a rede de catadores. Para a feira da música, que é mais um evento que nós vamos trabalhar, estamos construindo, isso tentando fechar com a Emlurb, para que todos os eventos no município de Fortaleza, sejam eles particulares ou públicos, nós estejamos lá, trabalhando com o catador de material reciclável e, consequentemente, fazendo um trabalho de educação ambiental. Foi a melhor forma de divulgar isso para cidadãos do município de Fortaleza (48 anos; secretário desde 2009).

\section{Perspectivas de Sustentabilidade das Associações: Dimensão Institucional}

Um dado institucional é aprimoramento da política interna de cada associação, começando pela reorganização de suas diretorias e conselhos fiscais e acompanhamento da Rede de Catadores, fazendo de forma consciente a passagem do mero amadorismo da distribuição de funções para o profissionalismo, que encara o perfil do empreendedor. Como se pode notar com o seguinte relato da diretora 5 da associação $E$ :

Então temos a presidente, o vice-presidente, o tesoureiro, o vice tesoureiro, o secretário, o vice-secretário e o conselho fiscal [...]. Nós temos uma contadora, ela é uma grande parceira [...] o controle é feito diariamente, nele é anotado todos os gastos, todas as pesagens, então a gente organiza no livro que a gente chama de caixa, entrada e saída de mercadoria, e vai fazendo o controle, e no final do mês, a gente leva pra contadora, e ela faz a parte corretamente que cabe ao contador fazer, é tudo controlado, entrada e saída de 
mercadoria, gasto, para que foi gasto com a manutenção, o que foi gasto com compra de mercadoria (45 anos; 10 anos de associação).

Relato da diretora 3 da associação C:

Nós temos um presidente, que é eu (Diretora 3), temos um tesoureiro, que é a Fatinha, temos uma secretária, que é a Vânia [...]. A gente viu que quanto mais gente, não ajudavam, então a gente diminuiu, ficou realmente aqueles que queriam ajudar. Aí tem o conselho fiscal, que é a Carina e dois rapazes que são catadores, o Henrique e o Bentinho (46 anos; 10 anos de associação).

No contexto institucional, surge uma nova perspectiva para ampliar a sustentabilidade das associações de catadores de resíduos sólidos, trata-se do cumprimento de uma das exigências do decreto 7.404, (2010) que regulamenta a lei nacional 12.305 (2010), capitulo III, seção I das disposições gerais, sobre a logística reversa:

Art. 13. A logística reversa é o instrumento de desenvolvimento econômico e social caracterizado pelo conjunto de ações, procedimentos e meios destinados a viabilizar a coleta e a restituição dos resíduos sólidos ao setor empresarial, para reaproveitamento, em seu ciclo ou em outros ciclos produtivos, ou outra destinação final ambientalmente adequada.

Observa-se que, para uma maior sustentabilidade das associações, é necessário um bom engajamento dessas ao programa de coleta, utilizando o emprego da logística reversa. A logística reversa exige da atividade de coleta de resíduos sólidos o uso de vasilhames adequados, transportes, bem como, conhecimento das classificações dos resíduos para o bom tratamento e recuperação industrial (CUNHA; CAIXETA FILHO, 2002). Assim, logística reversa surge para as associações como uma oportunidade de negócio gerando credibilidade por parte da exigência legal, que se amplia ao passar dos anos na sociedade brasileira.

A criação de novos galpões para o recolhimento de resíduos sólidos, por parte do gestor municipal, surge como mais um elemento que alcançará uma maior sustentabilidade das associações, considerando os quatro galpões que já estão em operação triagem do Jangurussu, Bom Sucesso, João XXIII e Planalto Universo, e outros irão ser aprovados no orçamento municipal e construídos em cada regional do município de Fortaleza.

Esta iniciativa exigirá das associações uma nova configuração organizacional, pois os galpões se tornam extensão de trabalho dos seus associados. Assim, o catador fica menos exposto ao sol, aos perigos da violência urbana e aos acidentes de trânsito. Pode-se notar o desejo dos envolvidos no projeto na afirmação a seguir:

Hoje nós temos em operação três centros de triagem no município de Fortaleza, uma articulação com alguns setores do comércio, isso tentando colaborar com a capacitação de materiais. Existe hoje a coleta implantada em quatro bairros do município de Fortaleza, que está sendo feita pela ECOFOR, certo, então esse material coletado é direcionado aos centros de triagem do município de Fortaleza que são três: Ascajan no Jangurussu, Maravilhas no Planalto Universo, e o centro de triagem no Bom Sucesso, na regional 3 (Responsável pelas políticas ambientais da SEUMA, 48 anos; secretário desde 2009).

Pelos relatos mencionados, percebe-se a urgência da implantação da coleta seletiva com a atuação direta das associações de catadores. A medida cria uma tendência a um maior associativismo e se criam parcerias entre as próprias associações, para o bom andamento dos galpões de triagem. Assim, o gerenciamento integrado dos resíduos sólidos minimizará o despejo indiscriminado de resíduos, maximizará 
o reuso e promoverá maior segurança ambiental, melhorando a atuação das associações e maximizando as estruturas de limpeza pública da cidade (LIMA, 2002).

A perspectiva institucional que surge como forte elemento de sustentabilidade das associações é o fortalecimento da Rede de Catadores, que foi fundada desde 2007. Ela surgiu para acolher os diversos grupos de catadores de resíduos sólidos que não possuem cadastro nacional de pessoa jurídica (CNPJ), por não terem associados suficientes, documentação oportuna e apoio mais institucional.

No entanto, a Rede de Catadores almeja a criação de uma cooperativa que, no mês de julho de 2013, conseguiu aprovação dos órgãos públicos fiscalizadores e tem por sede o galpão de triagem do bairro Bom Sucesso, feito estatuto com a escolha de uma diretoria e seu conselho fiscal.

A cooperativa dos catadores de resíduos sólidos surge como uma oportunidade sustentável da atividade dos catadores dos resíduos sólidos, uma vez que o leque de possibilidades de negociação, mediante emissão de notas fiscais e participação ampla de grandes volumes de coleta em instituições, é assegurado pela lei nacional 12.305 no que se trata da natureza cooperativista.

É bem verdade que o espirito para fazer a passagem da natureza associativista para a cooperativista é um processo que exige renúncia do individualismo, comprometimento e desejo de trabalho em equipe, e estas condições têm sido fomentadas a cada reunião do Fórum Lixo e Cidadania, promovido e participado por múltiplas representações do segmento da sociedade fortalezense no âmbito federal, estadual e municipal, bem como em ONGs e na iniciativa privada.

\begin{abstract}
A gente vem participando do Fórum Lixo e Cidadania que acontece toda primeira quartafeira de cada mês, lá no Centro de Pastoral Maria Mãe de Deus, da Arquidiocese. Tem a rede de catadores que também junta todos os outros grupos de catadores e aí, no dia 30 de cada mês, tem essa reunião, onde vários grupos de catadores se encontram para estarem discutindo o que é relacionado com os catadores, as nossas dificuldades, as políticas públicas, o que os catadores estão precisando, discutir preço de mercadoria, o que é que a gente pode melhorar em cada associação. Então a gente participa também do Movimento Nacional de Catadores, a gente participa através dos representantes estaduais que vão para os encontros lá fora (Diretora 5 da associação E, 45 anos; 10 anos de associação)
\end{abstract}

Nós estamos formando uma cooperativa também, essa cooperativa apoia a rede, apoia as associações (Diretor 2; associação B; 62 anos; 3 anos de associação).

Diante dos relatos acima registrados, percebe-se que a iniciativa de aglutinar as associações já legalizadas e seus grupos menores que não são legalizados numa cooperativa geraria uma ampliação no poder de negociação com a indústria de recicláveis, com posterior divisão da venda e lucros, bem como maior credibilidade da classe trabalhadora de catação de resíduos sólidos diante das autoridades públicas, dos setores privados e da sociedade civil.

\title{
DISCUSSÃO
}

As perspectivas de sustentabilidade para os próximos anos nas Associações de Catadores de Resíduos Sólidos para os próximos anos serão pautadas pela lei nacional de gestão de resíduos sólidos de no 12.305/ 2010, três macros perspectivas são visíveis, a saber: o contínuo apoio do Fórum Lixo e Cidadania, que exerce papel fundamental em relação a fazer intervenção entre associações e segmentos da sociedade interessados 
pelo assunto, bem como a criação de quatro galpões de triagem e o projeto de criar novos galpões em cada regional do município, facilitando o apoio socioeducativo aos catadores e saúde básica, por meio de equipes multidisciplinares em cada galpão. A terceira macro perspectiva é a criação da única cooperativa que unirá a rede de catadores e grupos menores de catadores para o aumento do poder de negociação, emissão de documentação fiscal e criação do espirito cooperativista entre os catadores.

Estas perspectivas acima destacadas se tornam necessárias na legitimação para a boa implantação do programa de coleta seletiva e sua sustentabilidade, sendo elas: O Contínuo apoio do Fórum Lixo e Cidadania, presentes nas capitais do Brasil pelo qual as associações debatem temas a fins e se aproximam para a implementação de projetos em comum, tomando ações que colaborem com os catadores, sociedade civil e parceiros institucionais. A criação dos galpões de triagem torna-se um vínculo urgente e necessário para a inclusão dos catadores no aspecto físico-estrutural, além de tirá-lo da rua pelo qual enfrenta situações de riscos da sua dignidade de trabalhador social. Estes galpões são inseridos na realidade periférica do município, além de facilitar a logística da coleta para com os associados- catadores que devem levar suas coletas para tais galpões a fim de comercializar os produtos e colaborar diretamente com uma maior aglutinação dos diversos projetos implantados para o bom andamento do plano de coleta seletiva.

A criação da Cooperativa Coopemares motiva às associações a boa capacitação dos seus associadoscatadores para que os mesmos sejam produtivos, além de motivar ao poder público na implementação de uma equipe multidisciplinar no campo sanitário-psico-social no acompanhamento dos que colaboram com esta cooperativa de forma interna na separação de material, bem como de forma extra, que são os que encaminham resíduos coletados para o galpão da cooperativa.

Na dimensão social, o horizonte da perspectiva dá-se pela contínua socialização entre o poder público e as entidades da sociedade civil; maior fiscalização do trabalho do menor, ou seja, coibição, para que as associações possam concorrer a editais; ampliação do projeto de alfabetização noturna para os catadores em associações; crescente mentalidade dos catadores de pertença - status - à associação e assistência básica de saúde e psicossocial nos galpões de triagem já construídos, além de promessa para os que serão construídos.

Na dimensão econômica, o amadorismo da gestão cede lugar a uma maior profissionalização contábil; cresce a quantidade de editais que oferecem investimentos nas associações; aumenta a procura de grupos menores para regularizarem no Cadastro Nacional de Pessoas Jurídicas; surge uma nova oportunidade de negócio nas associações, que é a coleta e o refino do óleo e gorduras residuais, além dos resíduos orgânicos para a compostagem; a atual gestão municipal se esforça para o aumento de número de ecopontos nos principais locais de produção de resíduos da cidade e para o aumento significativo das instalações, no Estado do Ceará, de indústrias de reciclagem, melhorando, por sua vez, o espaço de compra do material coletado pelas associações, sem ter a necessidade do esforço logístico de venda para outros estados brasileiros. 
$\mathrm{Na}$ dimensão ambiental, duas perspectivas aumentam as chances de sustentabilidade das associações de resíduos, a saber: a crescente conscientização do conceito de lixo e resíduo e o aprimoramento da nova visão da relevância do catador para a sociedade em geral.

Na dimensão institucional surgem como elementos que aumentam as perspectivas sustentáveis das associações o aprimoramento da política interna da associação pelo grupo gestor; o aumento, ainda que tímido, das parcerias entre as associações e indústrias no que tange à logística reversa; a nova organização das associações dentro dos galpões de triagem, superando o individualismo institucional e unindo experiências em vista do crescimento em torno da atividade. Torna-se visível o fortalecimento do poder de negociação entre a Rede de Catadores e o poder público e privado e, por fim, a operação da cooperativa que se encontra nos seus primeiros meses de operacionalização, no bairro Bom Sucesso, e que promete ser um canal para a formação do espírito associativista e cooperativista entre as associações e os grupos de catadores (Quadro 1).

Quadro 1: Perspectivas de Sustentabilidade das Associações.

\begin{tabular}{|c|c|c|c|}
\hline DIMENSÃO SOCIAL & ECONÔMICA & AMBIENTAL & INSTITUCIONAL \\
\hline $\begin{array}{l}\text { Contínua socialização } \\
\text { entre o poder público e } \\
\text { entidades da sociedade } \\
\text { civil. }\end{array}$ & $\begin{array}{l}\text { Transição do amadorismo } \\
\text { para uma maior } \\
\text { profissionalização contábil. }\end{array}$ & $\begin{array}{l}\text { Crescente conscientização do } \\
\text { conceito de lixo e resíduo sólido } \\
\text { reciclável. }\end{array}$ & $\begin{array}{c}\text { Aprimoramento } \\
\text { Da política interna da } \\
\text { associação pelo grupo gestor. }\end{array}$ \\
\hline $\begin{array}{l}\text { Maior fiscalização do } \\
\text { trabalho do menor- } \\
\text { coibição. }\end{array}$ & $\begin{array}{l}\text { Crescente oferecimento de } \\
\text { editais para investimentos. }\end{array}$ & $\begin{array}{l}\text { Aprimoramento da nova visão } \\
\text { da importância da função do } \\
\text { catador para a sociedade em } \\
\text { geral. }\end{array}$ & $\begin{array}{c}\text { Aumento da parceria entre as } \\
\text { associações e os fornecedores } \\
\text { no emprego da logística } \\
\text { reversa. }\end{array}$ \\
\hline $\begin{array}{l}\text { Ampliação do projeto de } \\
\text { alfabetização noturna para } \\
\text { os catadores em } \\
\text { associações. }\end{array}$ & $\begin{array}{l}\text { Aumento da formalização } \\
\text { no Cadastro Nacional de } \\
\text { Pessoas Jurídicas. }\end{array}$ & & $\begin{array}{c}\text { Nova organização das } \\
\text { associações dentro dos galpões } \\
\text { de triagem. }\end{array}$ \\
\hline $\begin{array}{c}\text { Crescente mentalidade de } \\
\text { pertença - status- inclusão } \\
\text { dos associados - } \\
\text { catadores. }\end{array}$ & $\begin{array}{c}\text { Oportunidade de Negócio: } \\
\text { óleo e gorduras residuais e } \\
\text { compostagem. }\end{array}$ & & $\begin{array}{l}\text { Fortalecimento do poder de } \\
\text { negociação da Rede de } \\
\text { Catadores com o poder público } \\
\text { e privado. }\end{array}$ \\
\hline \multirow{2}{*}{$\begin{array}{c}\text { Assistência básica de } \\
\text { saúde e psicossocial aos } \\
\text { associados nos galpões de } \\
\text { triagem. }\end{array}$} & $\begin{array}{l}\text { Aumento da coleta com a } \\
\text { instalação dos ecopontos. }\end{array}$ & & \multirow{2}{*}{$\begin{array}{l}\text { Operação da Cooperativa- Bom } \\
\text { Sucesso - maior poder de } \\
\text { emissão e controle fiscal. }\end{array}$} \\
\hline & $\begin{array}{c}\text { Novas instalações de } \\
\text { indústrias de reciclagem no } \\
\text { Estado do Ceará. }\end{array}$ & & \\
\hline
\end{tabular}

Destacam-se algumas iniciativas tomadas são valiosas, pelas associações, a rede de catadores, a formação do Fórum Lixo e Cidadania, bem como pelo engajamento e parceria de instituições religiosas e segmentos da sociedade civil. Entretanto, as associações necessitam a partir do ano de 2014 estarem mais pautadas pela Lei Nacional da Gestão de Resíduos Sólidos de no 12.305/ 2010 que tem por natureza o poder de corrigir e libertar as associações de uma dependência não produtiva do poder público partidário. Essa lei deve ser um marco divisor para a boa condução da coleta seletiva em nível domiciliar, comercial e industrial.

\section{CONSIDERAÇÕES FINAIS}

Em relação às dimensões: social, econômica, ambiental e institucional da sustentabilidade das associações de catadores de resíduos secos e úmidos, evidenciaram-se perspectivas que apoiam a iniciativa e continuo aperfeiçoamento da ação de cada associação pesquisada, os elementos pesquisados que 
sustentam as perspectivas positivas do plano de coleta seletiva, comercialização e reciclagem são positivos, agregam valor a associação em evidência.

Na realidade presente do impacto limitador da crise financeira presente no País, as perspectivas na área da coleta seletiva por parte das associações se revelaram como meio de combate ao descarte inútil de bens, de esforço contínuo para garantir um boa organização institucional, de buscas de novas parcerias com instituições sejam públicas ou privadas, além de serem percebidas como sinais de investimento diante de uma fatia do mercado em que nem sempre a sociedade sabe valorizar, mas que pelos demonstrativos contábeis anuais se pode inferir que a área de coleta seletiva, armazenamento, venda e reciclagem tem sido e continua a ser producente e promissora para os que nela discernem e atuam.

Espera-se que os interessados pelo presente assunto aprofundem quais limites nas dimensões social, econômica, ambiental e institucional podem ser cruciais na inviabilidade de manter a sustentabilidade das associações de coleta seletiva de resíduos secos e úmidos, uma vez que, a presente pesquisa não alcançou tais descobertas.

\section{REFERÊNCIAS}

BLEY JR, C.. Lixo no Brasil e no Mundo. Seminário Nacional de Resíduos Sólidos e Limpeza Urbana. São Paulo: 2001.

BOGDAN, R.; BIKLEN, S.. Investigação qualitativa em educação: uma introdução à teoria e aos métodos. Porto: Porto, 1994.

BRASIL. Lei 12.305/10. Política Nacional de Resíduos Sólidos. Brasília: Ministério do Meio Ambiente, 02 ago.2010.

BRASIL Decreto 7.404/10. Brasília: Ministério do Meio Ambiente, 23 dezembro de 2010.

BRASIL. Lei no 11.445/07. Brasília: Ministério do Meio Ambiente, 5 jan. 2007.

BRASIL. Lei de no 11.445/07. Brasília: Ministério do Meio Ambiente, 2007.

BRASIL. Lei de no 12.305/10. Brasília: Ministério do Meio Ambiente, 2010.

BRASIL. Decreto no 7.404/10. Brasília: Ministério do Meio Ambiente, 2010.

BRINGHENTI, J.. Coleta Seletiva de Resíduos Sólidos Urbanos: Aspectos Operacionais e da Participação da População. Tese (Doutorado em Saúde Pública) Universidade de São Paulo, São Paulo, 2004.

CAPRA, F.. A teia da vida: uma nova compreensão dos sistemas vivos. São Paulo: Amana-Key, 1996.

CAVALCANTI, C.. Sustentabilidade: mantra ou escolha moral? Uma abordagem ecológico-econômica. Estudos Avançados, São Paulo, v.26, n.74, 2012.

CAVEDON, N. R.. Antropologia para Administradores. Porto Alegre: EdUFRGS, 2003.
CONAMA. Conselho Nacional do Meio Ambiente. Resolução no. 358, de 29 de abril de 2005.

CUNHA, V.; CAIXETA FILHO, J. V.. Gerenciamento da coleta de resíduos sólidos urbanos: estruturação e aplicação de modelo não-linear de programação por metas. Gest. Prod., v.9, n.2, p.143-161, 2002.

GOUVEIA, N.. Saúde e meio ambiente nas cidades: os desafios da saúde ambiental. Saúde e Sociedade, v.8, n.1, p.49-61, 1999.

GRADVOHL, A.. Fortaleza- 15 anos à procura da Coleta Seletiva de Lixo. Fortaleza: Prograph, 2010.

IBAM. Instituto Brasileiro do Meio Ambiente. Gestão Integrada de Resíduos Sólidos: Manual Gerenciamento Integrado de Resíduos Sólidos. 2001.

IBGE. Instituto Brasileiro de Geografia e Estatística. Pesquisa Nacional de Saneamento Básico. Rio de Janeiro: 2010.

LIMA, C. R.. Gerenciamento Integrado de Resíduos Sólidos: apresentação do curso de capacitação em limpeza pública para profissionais de prefeituras. Vitória: 2002.

MINAYO, M. C.. Pesquisa Social: Teoria, método e criatividade. Rio de Janeiro: Vozes, 2004.

NASCIMENTO, E. P.. Trajetória da sustentabilidade: do ambiental ao social, do social ao econômico. Estudos Avançados, São Paulo, v.26, n.74, 2012.

PATTON, M.. Qualitative evaluation and research methods. Beverly Hills: Sage, 1990.

RIBEIRO, T. F.; LIMA, S. C.. Coleta Seletiva de Lixo Domiciliar: Estudo de Casos. Caminhos de Geografia, v.1, n.2, p.50-69, 2000. 
ROVIRIEGO, L. F. V.. Proposta de uma metodologia para a avaliação de sistemas de coleta seletiva de resíduos sólidos domiciliares. Dissertação (Mestrado em Engenharia) -

Universidade de São Paulo, São Carlos, 2006.

SANETAL. Plano Municipal de Gestão Integrada de Resíduos Sólidos de Fortaleza. Fortaleza: 2012.

SANETAL. Relatório IV. Fortaleza: 2012.

SANETAL. Plano Municipal de Gestão Integrada de Resíduos Sólidos de Fortaleza. Fortaleza: 2012.
STRAUSS, A.. Pesquisa qualitativa: técnicas e procedimentos para o desenvolvimento da teoria fundamentada. 2 ed. Porto Alegre: Artmed, 2008.

VEIGA, J. E.. Indicadores de Sustentabilidade. Estudos Avançados, São Paulo, v.24, n.68, 2010.

VERGARA, S. C.. Projetos e relatórios de pesquisa em administração. 3 ed. São Paulo: Atlas, 2000. 